\title{
ISLP COUNTRY COORDINATORS AS AMBASSADORS OF STATISTICAL LITERACY
}

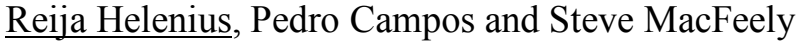 \\ Statistics Finland \\ University of Porto and Statistics Portugal \\ UN Conference on Trade and Development and University College Cork \\ reija.helenius@stat.fi
}

The ISLP (International Statistical Literacy Project) was established in 1994 by the ISI. The project operates under the IASE. In 2009, the project was strengthened by setting up a threeperson executive team and a network of country coordinators for the project. At the moment, the ISLP has over 90 country coordinators on all continents. Their duty is to be promoters of statistical literacy in their countries. The aim of this presentation is to describe and analyse the activity of country coordinators and ways of advancing statistical literacy in each country. In 2016, the ISLP asked for reports from country coordinators on their activity and received almost 50 responses. Over one-half of the reports came from developing countries and a significant part from Africa. The paper presents a summary of the country coordinators' reports.

\section{INTRODUCTION}

The International Statistical Literacy Project (ISLP) is a project initiated by the International Association for Statistical Education (IASE), which is the education section of the International Statistical Institute (ISI). ISLP operates in association with the International Association for Statistics Education (IASE), and the International Statistical Institute (ISI). The mission of the International Statistical Literacy Project (ISLP) is to support, create and participate in statistical literacy activities and promotion around the world. The project is run by a three-person executive team (writers of this paper). The project has a five-strong steering group appointed by the IASE. The most important resources for the project are 171 voluntary country coordinators who operate in 92 countries located in every continent. The project works in close cooperation with the national statistical offices, statistical societies, universities and training institutes.

The purpose of the ISLP is to advance particularly basic statistical literacy. There are several good definitions for statistical literacy (See e.g. Gal (2002), Schield (2010), Wahlman (1993)). When we are aiming to promote statistical literacy among broad audience, we can also speak about advancing people's working life skills and social abilities. Then, statistical literacy is a skill required by information society, which is needed in ordering, conducting and understanding various surveys and reports. At the minimum, statistical literacy is an everyday skill for following the news flow and for making everyday decisions (see Figure 1).

Basic statistical literacy a skill
requirement for people

Understanding of basic concepts and key figures

Ability to use and understand numerical and statistical data in everyday situations
Deeper usage skill a requirement for more people acting in information society

Knowledge of concepts, key figures, methods and presentations

Ability to use and produce numerical and statistical data in one's work duties and decision-making

FIGURE 1. Dimensions of Statistical Literacy (Helenius, 2016)

\section{NETWORK OF COUNTRY COORDINATORS}

The network of country coordinators was launched in 2009 by searching for voluntary country coordinators (ISLP 2017). At first, the principle was to have just one country coordinator in each country. Later it became possible to have several country coordinators for a country, and there are now country coordinator teams in various countries. 
The coverage of country coordinators by continent varies. European and African countries and different areas of Russia are already fairly fully involved in the activity. Europe has 51 and Africa 59 country coordinators. Of individual countries, Russia has the most country coordinators, 29. The activity in North America is currently low compared to other continents. The language barrier restricts communication with Asia and South America. For South America, the operation has been activated by naming a specific continent coordinator for the continent. The ISLP has also employed a Spanish-speaking undergraduate trainee for two years in a row to intensify communication. In addition, one member of the ISLP Executive Team is Portuguese speaking.

Table 1 shows the countries participating in the ISLP and the numbers of country coordinators. In total, there are 171 coordinators across 92 countries. Country and coordinator counts for each continent (treating the Americas together) appear at the bottom of each column.

Table 1: Countries and Numbers of Coordinators

\begin{tabular}{|c|c|c|c|c|c|c|c|c|c|}
\hline Africa & & Asia & & Europe & & Americas & & Oceania & \\
\hline Algeria & 1 & Bangladesh & 1 & Armenia & 1 & Canada & 1 & Australia & 1 \\
\hline Angola/ & & Bhutan & 2 & Austria & 1 & Costa Rica & 1 & New Zealand & 2 \\
\hline Cape Verde & 1 & India & 3 & $\begin{array}{l}\text { Czech } \\
\text { Republic }\end{array}$ & 1 & Haiti & 1 & $\begin{array}{l}\text { Papua New } \\
\text { Guinea }\end{array}$ & 1 \\
\hline Benin & 2 & Indonesia & 1 & Estonia & 1 & Mexico & 2 & & \\
\hline Botswana & 1 & Iran & 2 & Finland & 3 & $\begin{array}{l}\text { Trinidad and } \\
\text { Tobago }\end{array}$ & 1 & & \\
\hline Burkina Faso & 2 & Japan & 1 & France & 1 & USA & 1 & & \\
\hline Burundi & 1 & Kazakhstan & 1 & Georgia & 1 & & & & \\
\hline Cameroon & 1 & Kuwait & 1 & Germany & 1 & Argentina & 2 & & \\
\hline Chad & 2 & Malaysia & 1 & Hungary & 1 & Brazil & 4 & & \\
\hline Congo & 1 & Nepal & 2 & Ireland & 2 & Chile & 2 & & \\
\hline Egypt & 2 & Pakistan & 3 & Italy & 2 & Colombia & 2 & & \\
\hline Ethiopia & 2 & Palestine & 1 & Malta & 2 & Ecuador & 1 & & \\
\hline Ghana & 2 & Philippines & 1 & Norway & 1 & Peru & 1 & & \\
\hline Ivory Coast & 1 & Russia & 13 & Poland & 1 & Uruguay & 1 & & \\
\hline Kenya & 3 & Saudi Arabia & 1 & Portugal & 1 & & & & \\
\hline Lesotho & 2 & South Korea & 2 & Romania & 1 & & & & \\
\hline Malawi & 2 & Sri Lanka & 1 & Russia & 16 & & & & \\
\hline Mali & 1 & & & Serbia & 1 & & & & \\
\hline Morocco & 1 & & & Slovakia & 1 & & & & \\
\hline Mozambique & 1 & & & Slovenia & 1 & & & & \\
\hline Nigeria & 6 & & & Spain & 3 & & & & \\
\hline Niger & 1 & & & Sweden & 1 & & & & \\
\hline Republic & & & & & & & & & \\
\hline Rwanda & 1 & & & Turkey & 3 & & & & \\
\hline Senegal & 2 & & & UK & 2 & & & & \\
\hline Sierra Leone & 1 & & & Ukraine & 2 & & & & \\
\hline Somali & 1 & & & & & & & & \\
\hline South Africa & 5 & & & & & & & & \\
\hline Swaziland & 1 & & & & & & & & \\
\hline Tanzania & 5 & & & & & & & & \\
\hline Gambia & 1 & & & & & & & & \\
\hline Togo & 2 & & & & & & & & \\
\hline Uganda & 2 & & & & & & & & \\
\hline Zambia & 1 & & & & & & & & \\
\hline Zimbabwe & 1 & & & & & & & & \\
\hline 34 & 59 & 17 & 37 & 25 & 51 & 13 & 20 & 3 & 4 \\
\hline
\end{tabular}

TABLE 1. ISLP Network

\section{Tasks of country coordinators}

The tasks of country coordinator are to (ISLP 2017):

- Improve statistical literacy

- Give suggestions and ideas how to develop ISLP

- Advance and implement ISLP plans within own country/region 
- Provide informing material (e.g. on coming events, the country's ISLP activities) to the ISLP team and the ISLP Newsletter.

The country coordinators have free hands in organising their activities. Many countries belonging to the network especially promote statistical literacy among young people. In the last few years, the ISLP has also wanted to highlight the promotion of statistical literacy on all social fronts. One of the key tasks of the network is to share good practices and learn from each other. Every second year, the ISLP grants the Best Cooperative Project Award to the best practice or project that promotes statistical literacy. Portugal was awarded in 2015 by the ISLP for their popular statistical exhibition Explorística.

Why does the ISLP and promoting of statistical literacy motivate country coordinators?

We asked a few country coordinators what they felt about their participation in the activities of the ISLP and what motivates them to promote statistical literacy. Elieza Paul Milonga (personal communication, June 4, 2017) from Tanzania tells us why he wants to be involved in the network: "As an official statistician, I can see how statistics, data and statistical literacy is becoming the soul of enquiry, arguing and reasoning in a modern world, however, the data and statistical literacy is poorly understood by the public, media and many in leadership positions in the public and private hierarchy, particularly in developing countries. By understanding problems encountered in everyday life due to lack of statistical literacy, I have decided to volunteer and be an agent of change to enable citizens in my country to be statistically literates (...)",

Hugo Hernández (personal communication, June 4, 2017) from Mexico describes his experiences like this: "Sometimes I have to give a talk or a conference, some of them regarding the ISLP, and I use to start with H. G. Wells' quote "Statistical thinking will one day be as necessary for efficient citizenship as the ability to read and write". (...) All our theory, all data out of a context, are completely useless to the common citizen or even to researchers in non-mathematical areas; the importance relies on what our theory and data are saying about some real life situation. So, if we can provide some help to develop the capacity of reading statistics results, despite of the statistical theory behind, we will be helping to improve the efficient citizenship that H. G. Wells stated in his quote".

The country coordinator for Iran, Afshin Ashofteh (personal communication, June 7, 2017) explains the significance of statistical literacy as follows: "Let me tell you the truth. Statistical literacy is nothing except knowing about a very small zone of sciences, though this small piece of huge puzzle has been impressing the indispensable foundations of vast daily activities of human beings, not only in the fields of data science and statistics but also in the capability of understanding and perspective taking, each of which is entirely vital for the international development process. (...) Let's be honest to ourselves, what could be more interesting indeed to perceive a WORLD full of GOOD DATA in the result of which people can find BETTER LIFE on the base of marriage of technology and this small zone of sciences, i.e. statistical literacy?"

\section{SUMMARY OF THE ACTIVITIES AND EXPRIENCES OF THE COUNTRY COORDINATORS}

\section{Inquiry to country coordinators}

In summer 2016, the project carried out an inquiry to country coordinators to find out:

- What type of activities country coordinators organise in their country

- Countries' good practices

- Possible obstacles to the country coordinator activity.

The functioning of contact details, willingness to continue in the network and the activeness of the network in general were explored at the same time. A written report was received from 49 countries. A special number of the ISLP Newsletter compiled from these reports was published in March 2017 (ISLP Newsletter 2017). The reports display inspiring examples of statistical literacy projects, and a set of good practices widely used around the world. Such practices to educate youth on statistics and promote statistical literacy and education go from highlevel conferences and books to games, quizzes, digital learning environments, competitions, 
websites and summer camps for children and young people. Good methods are shared across borders but new ones are also developed. Statistics students participate in many of these projects, which are organised in cooperation between schools, universities, statistical and educational institutions as well as non-governmental organisations.

\section{Examples of different countries' activities}

There are numerous great examples of statistical literacy projects, it is only possible to mention a few. In Brazil, the Statistical Multimedia Literacy programme targets youth in vulnerable situations, aiming to improve their statistical skills and teach critical citizenship. The combination of multimedia technologies and real-life examples enhance the learning experience. (Porciúncula \& Samá 2017.) In Ecuador, there is a teaching programme for children under the topic: "We are different", explaining the cultural diversity with statistics and visualisation. The program also includes songs to be used as educative material, describing societal issues in light of statistics. (Pérez Caicer 2017.) In Germany, a school reform has included statistics education in all levels from primary to upper secondary schools. Universities from Germany, Hungary, Israel, Portugal and the UK, with support from the ERASMUS program, will launch the ProCivicStat project to create a digital learning environment to engage citizens, teachers and students in statistical thinking. (Ullman 2017.) Norway increasingly uses infographics in statistics, as well as in overall education system (Stabell 2017). Also, Ireland has reformed the mathematics and statistics education in schools, and has achieved to engage students widely in statistics via the ISLP competition (Leavy \& McCuirc 2017).

Spain has successfully established the Statistical Olympics for secondary school students to teach them to analyse statistics (Serradó Bayés 2017). India held summer camps for students where statistical thinking was taught (Hooda \& Singh Kaurav 2017). The National Statistics Office of Malta developed its first interactive online platform, where it is possible to compare population between different parts of the Maltese Islands (Borg 2017). The Czech Republic created a "MiniCensus" for young people, to improve their understanding of how statistics relate to every-day life of people (Fischer 2017). Australia, in turn, held a conference in 2016 with participants from elementary school teachers to industry leaders to brainstorm about how to develop statistics education in the country (Howley 2017).

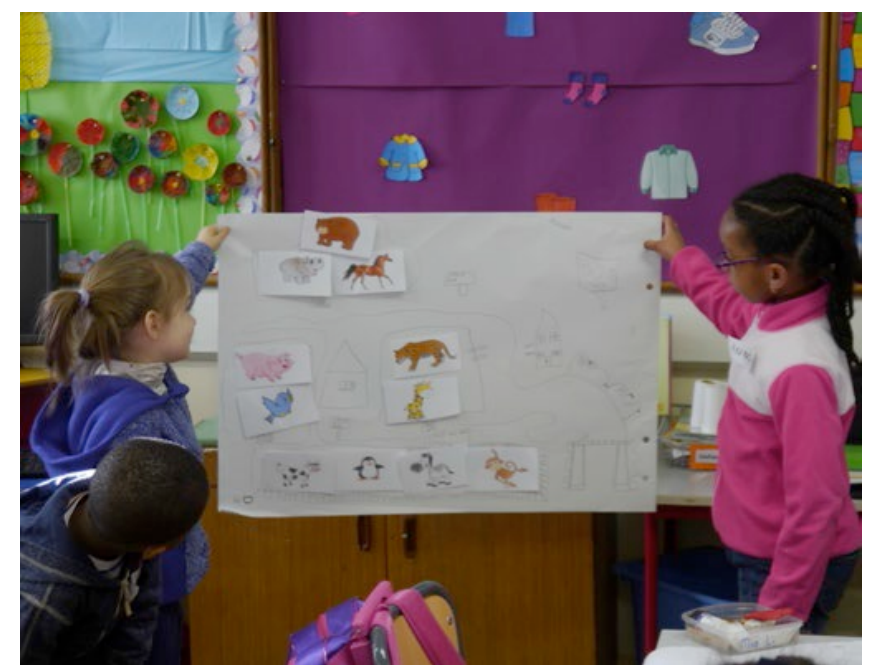

FIGURE 1. Learning statistics since young age (photo: Leavy \& McCuirc 2017).

\section{ISLP poster competitions}

The ISLP poster competition has proved to be a successful way to engage the attention of young people in statistics. Since its establishment in 2010 to 2011, the number of participants has grown from the initial 5,000 students from 17 countries, to more than 12,000 students from 23 countries. Now seven competitions have been organised, five of which have been poster competitions. 
The poster competition provides a good instrument for teaching how to conduct statistical research from the formation of the research problem to the selection of the research method, analysis of data, presentation and drawing of conclusions. The competition is equally suitable for developed and developing countries because the tool with which the poster is made is not decisive in the competition but the work as a whole.

According to the report of MacFeelyn et al. (2016), it is not surprising that a key factor of success to organise statistical literacy competitions is cooperation with the different organisations (for example, in Finland, India, Japan, Russia, Spain, Italy, Ireland and New Zealand). Typically, these institutions include: National Statistical Institutes (NSIs), secondary and tertiary educational institutes, Government departments for Education (and/or Science/Technology), Statistical associations and other organisations, such as Mathematics Curriculum Boards and sponsors. Be it to raise finance, provide data, bring technical or logistical expertise or assist in marketing and media capture, many institutions can bring something useful to the table.

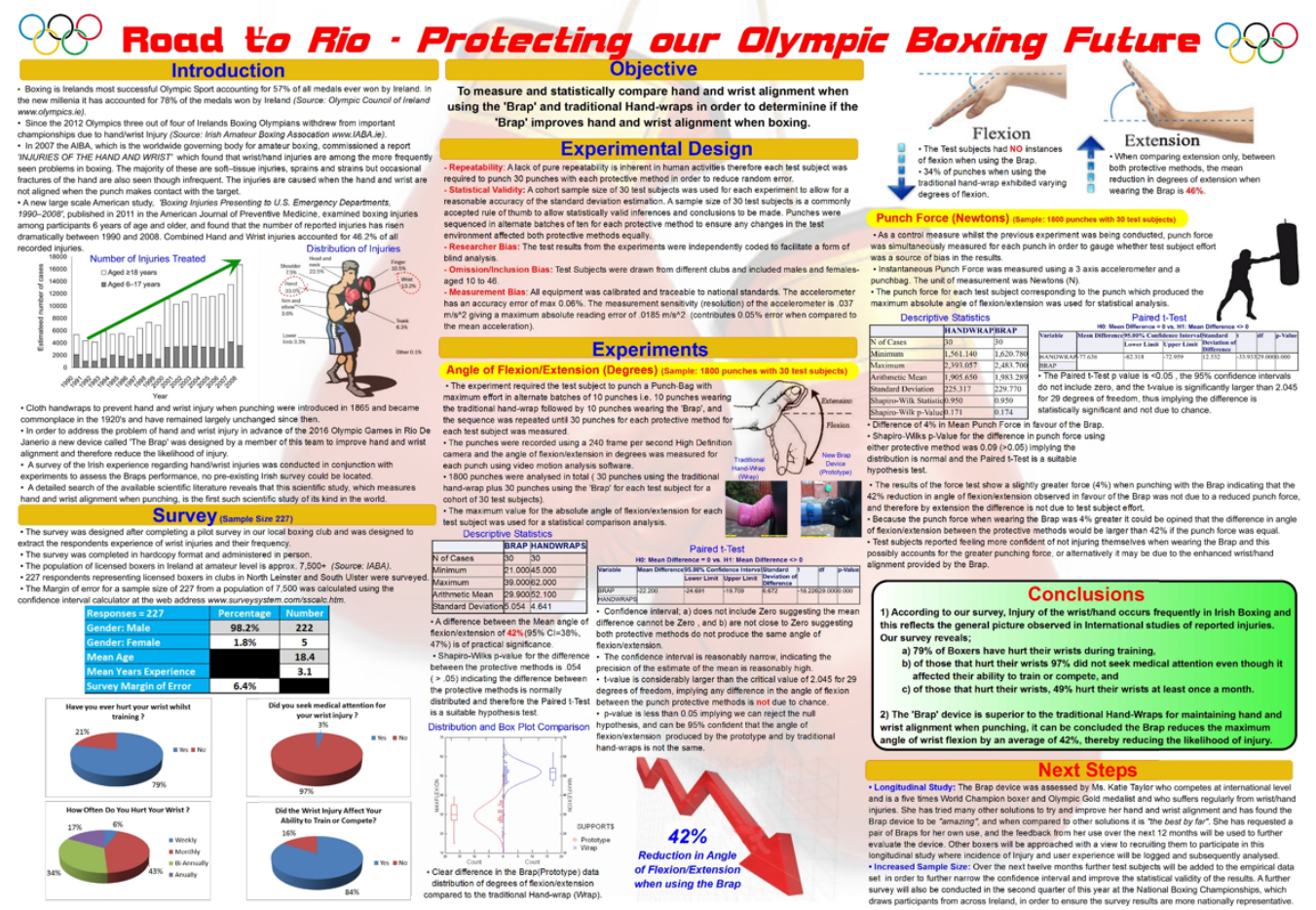

FIGURE 2. Winner poster 2014 to 2015 from Ireland. Older age division (age 15 to 18).

\section{Restrictions and possibilities}

In different countries, the work to promote statistical literacy takes different trajectories. Developed and developing countries face different kinds of challenges in promoting statistics education and literacy. In some countries, the challenge has been that teachers do not have sufficient knowledge or methods for statistical education. For this reason, many countries have organised courses and workshops for teachers. Resource constraints and administrative rigidity are also challenges faced by some. Because the starting points are different in various countries, the objectives of the activity are also divergent. Developing countries wish to have ready-made learning material in their own language. The ISLP resources website has been under development in 2015 to 2016 and it is hoped it will gradually bring solutions to distributing learning material as well. On the other hand, the majority of the material is in English, which restricts its use.

Developed countries are coming up with various applications to support learning for the needs of young people and others. Distributing the applications to wider use is more complicated because solutions in one country do not necessarily serve other countries. Sharing of good practices is an advisable target, because the content of teaching is the same for all - statistics and their understanding. A good example was at its time the establishment of the CensusAtSchool cooperation network, for example. 
There is still work to be done in communicating statistics and developing strategies. For wider public statistics can appear complicated to understand, and in some developing countries statistical literacy has been low. Gender inequality is also related to access in statistical education. Despite this, all around there are initiatives to improve statistical literacy in one way or another, and progress is being made. Ghana, for example, has despite challenges successfully launched a statistical ICT workshop for young statisticians to improve their software skills (Novignon 2017). Gambia is in the process of establishing an association of young statisticians, who will work to promote statistical literacy in cooperation with schools, universities and the national statistical institutions (Mulva 2017). In Iran, the first book about statistical literacy in the Persian language was published in 2016. This was accompanied with the launch of the Persian website dedicated to statistical literacy and the founding of the House of Statistics in the scientific city of Isfahan. (Ashofteh 2017.) Haiti has launched its first statistical MOOC (Massive Online Open Course), accessible for everyone interested in statistics (Bolivar 2017). In Togo, statistical literacy is promoted by training of Statistics Techniques Agents within the government (Plambou Anissa 2017).

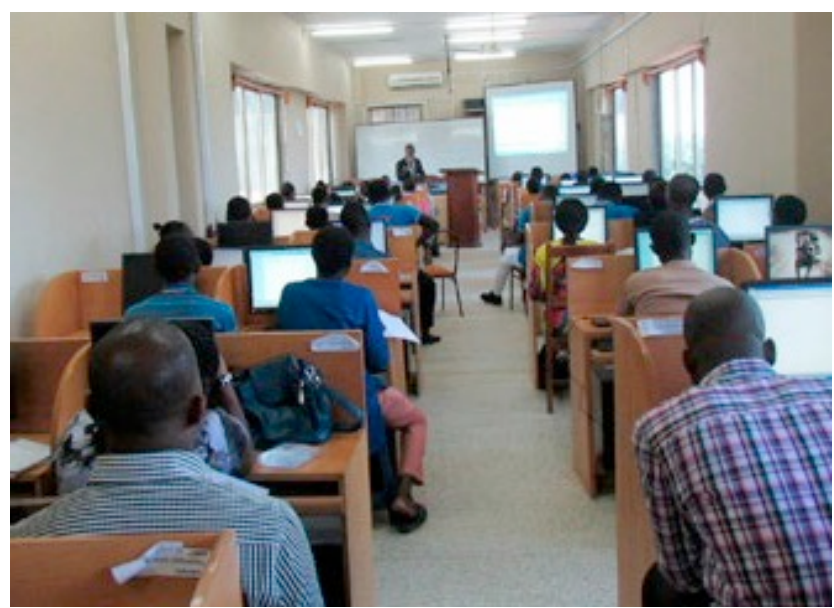

FIGURE 3. ICT Workshop for young statisticians in Ghana (photo: Novignon 2017).

\section{CONCLUSION}

The ISLP network of country coordinators offers a vast opportunity for cooperation in the field of statistics across continents, countries and cultures. The network is valuable, because it is combined by a common wish to promote statistical literacy all over the world. All volunteers are welcome to the network. To develop the activity further we should find solutions to support this voluntary work. For this, we need outside funding and sponsors to enable consulting in developing countries, to translate learning materials to different languages and to support the participation of developing countries in scientific conferences.

\section{REFERENCES}

Ashofteh, A. (2017) News on IRAN. ISLP Newsletter, Vol. 9.1., pp. 24-25.

Bolivar, B. (2017) Haiti. ISLP Newsletter, Vol. 9.1., p. 23.

Fischer, J. (2017) Czech Statistical Literacy Improvement. ISLP Newsletter, Vol. 9.1., p. 14.

Gal, I. (2002) Adults' Statistical Literacy: Meanings, Components, and Responsibilities. International Statistical Review, 70, 1, 1-25.

Helenius, R (2016) Facing the Future with Knowledge - Cooperation with Educational Institutions. Nordiskt statistikermöte 2016.

Hooda, D. S. \& Singh Kaurav R. P. (2017) Activities for Developing Statistical Literacy in India. ISLP Newsletter, Vol. 9.1., p. 23.

Howley, P. (2017) Australian Report. ISLP Newsletter, Vol. 9.1., p. 7.

ISLP (2017). The second call for country representatives.

https://iase-web.org/islp/Activities.php? $p=$ Call_for_Country_Coordinators, accessed June 7, 2017. 
Leavy, A. \& McCuirc, E. (2017) Ireland Report. ISLP Newsletter, Vol. 9.1., p.26.

MacFeely, S., Campos, P. \& Helenius, R. (2017). Experiences and Key Success Factors in Improving Statistical Literacy: The Case of the ISLP Poster Competition. Will be published in the Statistical Education Research Journal in 2017.

Mulva, S. N. (2017) Greetings from GAMBIA. ISLP Newsletter, Vol. 9.1., p. 18.

Novignon, J. (2017) Report on how Statistical Literacy has been improved in Ghana. ISLP Newsletter, Vol. 9.1., pp. 21-22.

Pérez Caicer, W. (2017) Alfabetización de Estadística en Ecuador. ISLP Newsletter, Vol. 9.1., p. 15.

Plambou Anissa, B. Statistical Literacy Promotion in Togo. ISLP Newsletter, Vol. 9.1., p. 48.

Porciúncula, M. \& Samá, S. (2017) Leme. Statistical Multimedia Literacy. ISLP Newsletter, Vol. 9.1., pp. 9-10.

Schield, M. (2010). Assessing Statistical Literacy: Take Care. In: Assessment Methods in Statistical Education. Wiley.

Serradó Bayés, A. (2017). Great News from Spain! ISLP Newsletter, Vol. 9.1., p. 43.

Stabell, C. (2017). Activities of Statistics Norway to Improve Statistical Literacy. ISLP Newsletter, Vol. 9.1., p. 33.

Ullman, P. (2017). On the Improvement of Statistical Literacy in Germany. ISLP Newsletter, Vol. 9.1., p. 20.

Wallman, K. (1993). Enhancing Statistical Literacy: Enriching Our Society. Journal of the American Statistical Association, 88, 421, 1-8. 